\title{
Experimental Study on Restoring Force Model for Outer Shell Beam-Column Joints of Steel Structure
}

\author{
D. Zhang ${ }^{1^{*}}$, Z. Tao ${ }^{1}$, G. Zhang ${ }^{2}$ and J.C. Li $^{3}$ \\ ${ }^{I}$ Faculty of Civil Engineering and Mechanics, Kunming University of Science and Technology, Kunming 650500, China \\ ${ }^{2}$ School of Engineering, University of Southampton, Southampton SO17 1BJ, UK \\ ${ }^{3}$ Yunnan Highway Development and Investment Co. Ltd, Kunming 650500, China
}

Received 14 January 2017; Accepted 19 March 2017

\begin{abstract}
Restoring force model is the foundation of the elasto-plastic time history analysis of the steel structure or the member. However, the restoring force curves obtained from the experiments are complex and difficult to be directly used for the seismic calculation of the structure. In order to simplify the restoring force characteristics of the outer shell beam-column joints of a steel structure, a computational model based on the properties of the test curves and described by a mathematical method was presented. Through the quasi-static test method, the seismic performance of four outer shell joints under cyclic loading was studied, and the stress stage and failure mode were analyzed. Then, a tri-linear restoring force model accorded with the skeleton curve characteristics was established. Based on this model, the stiffness degradation rules of the specimens under reciprocating load were deduced by regression statistical method. In addition, the hysteresis curve models of the joints were calculated and compared with the experimental results. The results show that the stress process of the specimen is divided into three stages: elasticity, yield, and plasticity. Moreover, the tri-linear skeleton curve models are in good agreement with the experimental results, which reflect the stress properties of the joints at different stages. Meanwhile, the hysteresis models considering stiffness degradation describe the hysteresis rules, these rules are approximately the same as the hysteresis curves obtained from the tests. The proposed restoring force model can accurately reflect the moment-rotation relationships of the specimens, providing theoretical references for the nonlinear seismic response analysis of the outer shell joints.
\end{abstract}

Keywords: Beam-column joint, Outer shell, Restoring force model, Skeleton curves, Hysteresis curves

\section{Introduction}

Beam-column joint is an important part of the structural system that is located at the junction of the beam and column Different connection forms have great influences on the seismic performance of steel structure. In order to improve the adverse effects of traditional steel joints due to on-site welding, a new outer shell joint of square steel tubular column-H steel beam was proposed [1]. The beam and column of this new type of joint were connected by $\mathrm{T}$ shaped steel and full bolts. Furthermore, the steel plates were assembled in the core area of the square tubular column to enhance the stiffness of the joint region. Given the excellent seismic performance of outer shell joints, the application in seismic area is becoming more and more extensive. Moreover, the restoring force model of the outer shell joint is the basis of elasto-plastic seismic response analysis of the steel structure, it analyzes the moment-rotation hysteresis curve of the joint reasonably and provides the basic theory and evaluation criteria for the selection of components, hence, it is the key issue to solve the application of outer

*E-mail address: zd123kmust@163.com

ISSN: 1791-2377 @ 2017 Eastern Macedonia and Thrace Institute of Technology. All rights reserved. shell joints. However, the restoring force curves obtained from the experimental or finite element methods are usually complicated and difficult to be directly applied in the engineering design. Therefore, proposing a restoring force model of outer shell joints based on the mathematical method is a major issue that needs to be addressed.

In recent years, domestic and foreign scholars have proposed a variety of restoring force models of structure or component, such as bilinear [2-3], tri-linear [4-5], and curve [6]. The proposed models have improved the structural seismic stress analysis theory. Among them, the curve-type restoring force model has a continuous changing stiffness, hence, the calculated results are close to the actual situation. However, the formula is complicated, and the calculated amount is large, causing many inconveniences in the elastoplastic analysis. The polyline models are widely used in the field of engineering design due to its simplicity and practicality. However, these are models mostly used in the reinforced concrete structures [7]. Due to the brittleness of the concrete material, the yield point of the skeleton curve is clear, and the tri-linear model is usually selected. Nevertheless, the bilinear model is always chosen for the steel joint because of its good ductility, but it does not consider the stiffness and strength degradation, hence, it only applies to cases with less number of cyclic loading. 
Based on the above reasons, the present study established a tri-linear restoring force model, considering the stiffness degradation under the low-cycle reciprocating loading experiment, which is suitable for the outer shell joint Furthermore, this study aims to accurately describe the actual stress characteristics of steel joints and optimize the analysis method of skeleton curves and hysteresis rules in different connection forms.

\section{State of the art}

The seismic responses of the structure mainly depend on the hysteresis characteristics of the components and the accuracy of the restoring force model. Sivaselvan [8] presented several hysteresis models derived from the energy method, and they were commonly applied in typical plastic models. Ceravolo et al. [9] aimed at evaluating the influences of different hysteretic systems on the seismic performance by establishing various restoring force models. At the same time, the safety performance of the structure is closely related to the energy dissipation capacity of the isolation devices. Kumar [10] and Fan [11] established the restoring force models of elastic seismic isolation bearing and new energy dissipation device, respectively. And these models described the mechanical properties of the devices. Previous studies show the accurate calculations of the corresponding mathematical models in order to describe the performance level of the component. However, the application of the models in the main structure is not mentioned in the analysis of results.

Therefore, domestic and foreign scholars began to study the restoring force models of structure or component. In the view of the overall structure, Wang et al. [12] conducted a shaking table test on the cast-in-situ recycled aggregate concrete frame and obtained the feature points of a four-linetyped skeleton curve. Then, the stiffness degradation of the hysteresis model was defined. Loh et al. [13] employed the modified Bouc-Wen hysteresis model to the shaking table test data of the reinforced concrete frame structure. This model evaluated the physical parameters, including the stiffness degradation, strength deterioration, and pinching hysteresis. While Kumar et al. [14] examined the influences of ductility reduction factor and ductility demand on masonry-infilled reinforced concrete frame by developing a simple force-deformation model with three control points. In addition to the frame structure, the studies of the restoring force models were also applied to the load-bearing members subjected to repeated alternating loads. Xiao et al. [15] proposed a normalized tri-linear skeleton curve model based on the low-cycle reciprocating loading test. This model better reflect the skeleton curve characteristics of semiprecast column with recycled aggregate concrete. Mergos et al. [16] established a moment-curvature hysteresis model and a shear force-shear strain hysteresis model to discuss the shear-flexure interaction effects in the equivalent frame models of slender reinforced concrete walls. Based on the material nonlinear model, Kashani et al. [17] simulated the buckling and degradation phenomenon of corroded reinforcing bars by a new phenomenological hysteretic model. Li et al. [18] studied the hysteresis behavior of inplane loaded reinforced grouted multi-ribbed aerated concrete block masonry walls based on the quasi-static test data. Furthermore, they proposed a four-linear degenerate restoring force model, which accurately reflected the hysteresis behavior and skeleton curve characteristics. The restoring force models established above are mainly concentrated in the concrete structure or component. Notably, the stress state of the joint is more complicated than that of the wall or the column. However, only a few related researches are available to explain this finding [19]. In addition, the restoring force models of the beam-column joints of steel structure are not mentioned.

At present, the tri-linear model is widely used in the study of restoring force models of different components due to its simplicity and practicality. Yu et al. [20] used the method of theoretical calculation and regression analysis of test data to provide a tri-linear restoring force model of the polyvinyl chloride-carbon fiber reinforced polymer (PVCCFRP) confined reinforced concrete columns based on Clough degeneration model, including the calculation method of unloading stiffness and hysteresis rules. Based on the test results, $\mathrm{Su}$ et al. [21] presented a degenerated trilinear restoring force model of concrete-filled square steel tubular short columns with binding bars. The hysteresis model was proven to be consistent with the experimental results. Lu et al. [22] conducted a low-cycle reciprocating loading test on the steel reinforced concrete columns, and they suggested a degrading tri-linear restoring force model, which could provide an accurate prediction of the test results. However, the skeleton curves and hysteresis rules of structural members are different, reflecting on the restoring force models are also distinguishing. The tri-linear models used in the previous studies contain the descending branch. By contrast, the descent segment of the skeleton curve of the steel tubular joint specimen is not obvious. This finding reveals that the steel tubular column is still in the strengthening stage when the ultimate bearing capacity is reached. Therefore, the tri-linear model needs to be combined with the actual stress characteristics of specific members.

To verify whether the restoring force model of the component is reasonable, it needs to be compared with the obtained skeleton and hysteresis curves. Zhou et al. [23] conducted a low-cycle reciprocating test on 12 circular reinforced concrete (RC) columns strengthened by CFRP strips. The test presented a tri-linear restoring force model and elaborated feature points, stiffness degradation, and hysteresis rules, which were consistent with the experimental results. Based on the experiment, Li [24] established a tri-linear restoring force model of high-strength concrete column confined by butt-welded closed composite stirrups, the skeleton curve had various stages, namely, elasticity, strengthening, and strength degradation, and the model can better reflect the hysteretic behavior of columns. The restoring force models obtained in the above studies have been verified by the experiments. However, the skeleton curves were the only components compared and analyzed. Notably, the restoring force model is composed of two parts: the skeleton curve and the hysteresis rule. The hysteretic curves can reflect the stiffness and strength degradation of the component, as well as the sliding phenomenon. Therefore, the restoring force models need to be further explored.

Given the above reasons, the stress process and the failure mode of the outer shell beam-column joints of steel structure were analyzed based on the quasi-static test results. The tri-linear restoring force model was also proposed, which was consistent with the stress characteristics of the outer shell joints. In addition, the regression analysis of the stiffness degradation rules in the experiment was carried out, and the regression equations of the skeleton and hysteresis 
curves were given. At the same time, the restoring force models were compared with the test curves to verify the accuracy, which laid the foundation for the elasto-plastic analysis of the outer shell joints.

The rest of the study is organized as follows: Section 3 describes the general situation of the low cycle loading test of the outer shell joints. Section 4 presents the skeleton and hysteresis curve models according to the characteristics of the test curves and stiffness degradation rules, and makes comparisons of the experimental results. Section 5 summarizes this study and provides relevant conclusions.

\section{Methodology}

The quasi-static test was carried out to apply the low-cycle reciprocating loads to the joint specimens. Then, the restoring force model was established based on the experimental results. The specimens were selected from the cross-shaped joints between the beam and column inflection points in the steel structure, and four test specimens were made. The square steel tubular column has a cross-sectional size of $300 \mathrm{~mm} \times 8 \mathrm{~mm}$, while the $\mathrm{H}$-shaped steel beam has a dimension of $248 \mathrm{~mm} \times 124 \mathrm{~mm} \times 5 \mathrm{~mm} \times 8 \mathrm{~mm}$. The beam-column joint was connected by $\mathrm{T}$-shaped steel and full bolts, and the T-shaped steel was set up with stiffener. The friction high-strength bolts with a grade of 10.9 were chosen. Furthermore, the connection used between the outer plate and column wall and the adjacent outer shells was welding seam, as shown in Fig. 1. According to whether filling concrete in the column, the specimens were divided into steel tubular joint (STJ) and concrete-filled steel tubular joint (CFSTJ). Each type of joint contained two specimens. The specimen parameters are shown in Table 1.

Fig. 1. Details of the outer shell joint

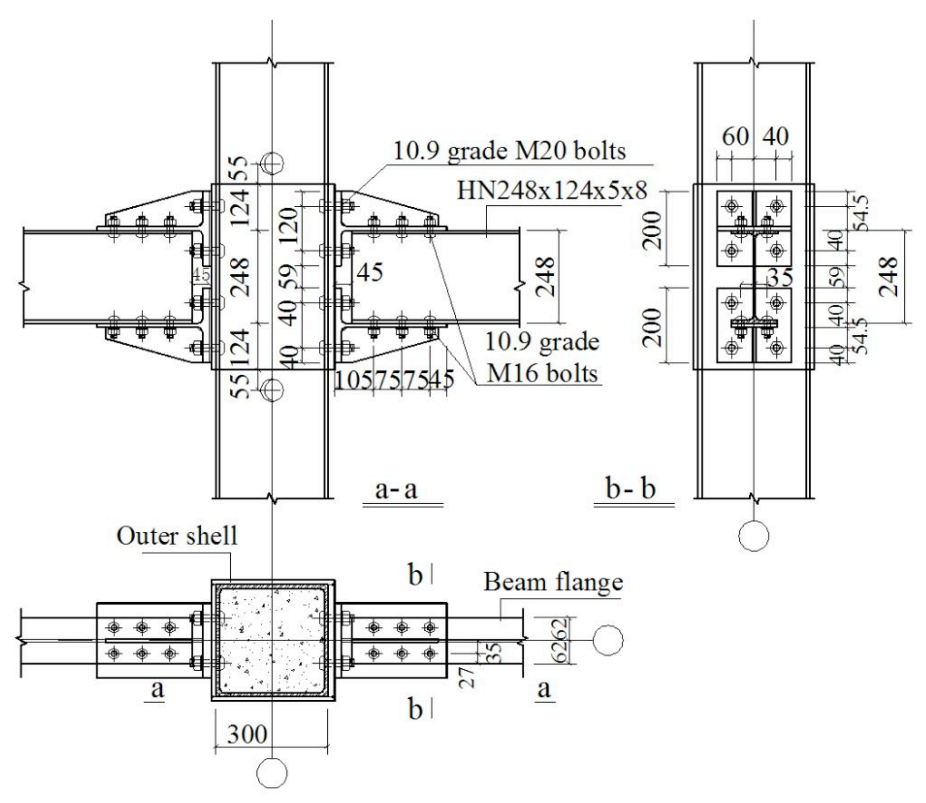

Table 1. Parameters of joint specimens ( $\mathrm{mm}$ )

\begin{tabular}{|c|c|c|c|c|c|c|c|c|c|}
\hline \multirow[b]{2}{*}{$\begin{array}{l}\text { Test } \\
\text { group }\end{array}$} & \multirow[b]{2}{*}{$\begin{array}{l}\text { Specimen } \\
\text { number }\end{array}$} & \multirow{2}{*}{$\begin{array}{l}\text { Colum } \\
\text { n } \\
\text { section }\end{array}$} & \multirow[b]{2}{*}{$\begin{array}{l}\text { Beam } \\
\text { section }\end{array}$} & \multicolumn{2}{|l|}{ Outer shell } & \multirow[b]{2}{*}{$\begin{array}{l}\text { T-shaped } \\
\text { steel web }\end{array}$} & \multirow[b]{2}{*}{$\begin{array}{l}\text { T-shaped } \\
\text { steel flange }\end{array}$} & \multicolumn{2}{|c|}{ High-strength bolt } \\
\hline & & & & $\begin{array}{l}\text { Column } \\
\text { flange side }\end{array}$ & $\begin{array}{l}\text { Column } \\
\text { web side }\end{array}$ & & & $\begin{array}{l}\text { T-shaped } \\
\text { steel flange }\end{array}$ & $\begin{array}{l}\text { T-shaped } \\
\text { steel web }\end{array}$ \\
\hline \multirow{2}{*}{ STJ } & STJ-1 & \multirow{4}{*}{$300 \times 8$} & \multirow{4}{*}{$\begin{array}{l}248 \times 124 \\
\times 5 \times 8\end{array}$} & \multirow{4}{*}{$496 \times 300 \times 12$} & \multirow{4}{*}{$496 \times 300 \times 8$} & \multirow{4}{*}{$300 \times 200 \times 11$} & \multirow{4}{*}{$200 \times 200 \times 17$} & \multirow{4}{*}{$4 \times \mathrm{M} 20$} & \multirow{4}{*}{$6 \times \mathrm{M} 16$} \\
\hline & STJ-2 & & & & & & & & \\
\hline \multirow{2}{*}{ CFSTJ } & CFSTJ-1 & & & & & & & & \\
\hline & CFSTJ-2 & & & & & & & & \\
\hline
\end{tabular}

Where $\mathrm{M}$ represents the nominal outside diameter of the bolt.

When the specimens were manufactured in the factory, the standard material specimens were fabricated according to the mechanical tensile test method. The hot rolled $\mathrm{H}$-section steel was chosen, and the material was Q345 (yield strength of $345 \mathrm{~N} / \mathrm{mm}^{2}$ ). All of the standard material specimens were processed at the same time as the specimens, and the surface was treated with rust removal. The mechanical properties of the material are shown in Table 2.

Table 2. Mechanical properties of steel

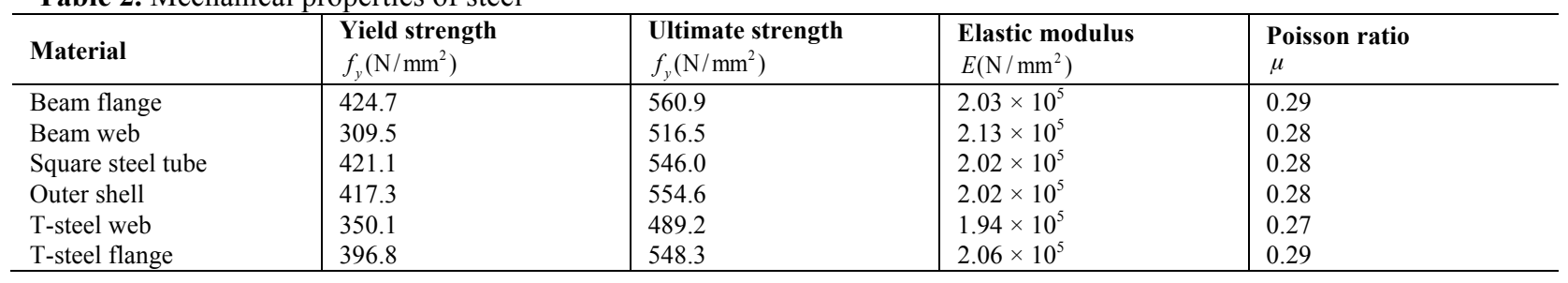

The experiment was performed according to the quasistatic test method. First, a constant axial load was applied to the top of the column. Then, the anti-symmetrical low-cycle reciprocating loads were applied at the free ends of the beam. 
In the mixed loading mode with control force and control displacement, the specimens were subjected to load control and graded loading before yielding. When the yield load $P_{y}$ was close, the loading was controlled by the displacement, the amplitude was applied in multiples of the yield displacement $\Delta_{y}$, and each loading level was cycled three

times. The loading mechanism is shown in Fig. 2. The test was stopped when the vertical load of the beam end was reduced to $85 \%$ of the peak load or the specimen could not guarantee stable loading.

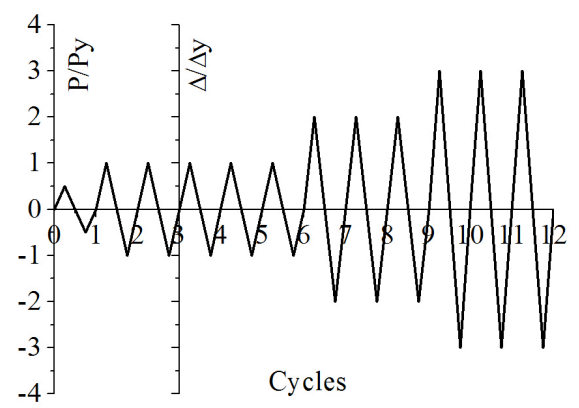

Fig. 2. Low-cycle reciprocating loading mechanism

\section{Result Analysis and Discussion}

\subsection{Failure mode}

The failure modes of the outer shell joints were analyzed based on the low-cycle reciprocating loading test, as shown in Fig. 3. The stress process can be divided into three stages: elasticity, yield, and plasticity. The failure characteristics of each stage were briefly summarized by specimen STJ-1.

(1) Elastic stage

In the initial loading stage, the specimen had no obvious deformation, the moment-rotation hysteresis curve was in the elastic range, and the initial stiffness was large. As the load increased, a slight gap was observed between the Tsteel flange and the column wall on the tensile side, as seen in Fig. 3 (a). The friction between the beam and column was gradually transmitted to the bolts and the T-type steel.

(2) Yield stage

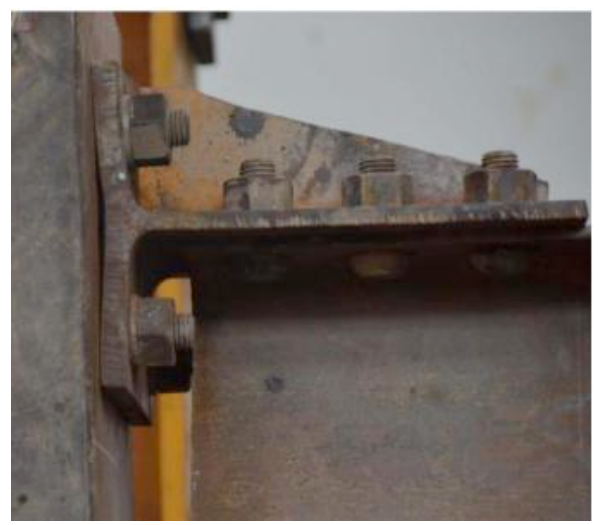

(a)
When the displacement was loaded to $24 \mathrm{~mm}$, the bending moment corresponding to the beam end was $87.3 \mathrm{kN} \cdot \mathrm{m}$. Moreover, the T-steel flange of the tensile zone was pulled out in a slight arc. Due to the reciprocating load under the action of tension and compression alternately, the high-strength bolts connecting the T-steel and the beam flange had a tendency to slide, and each subsequent cycle was accompanied by a slight slip. The extrusion deformation occurred between the bolt and the hole wall of the lower flange of the H-shaped beam, as seen in Fig. 3(b). A slight buckling of the beam flange was observed when the specimen was in the yield stage.

(3) Plastic stage

With continued loading, obvious traces of slip in the outermost row of bolts were identified. In addition, a significant buckling occurred at the beam flange, as shown in Fig. 3(c). When the displacement was loaded to $64 \mathrm{~mm}$, a visible gap was observed between the T-steel flange and column wall. As the deformation of the column wall increased, the weld in the lower end of the outer shell of the column flange in the tensile zone was cracked, as shown in Fig. 3(d). When loading was at $90 \mathrm{~mm}$, the corresponding beam ends had reached the limit bending moment value of $148.1 \mathrm{kN} \cdot \mathrm{m}$, and the beam flange at the end of T-steel web had formed an obvious plastic hinge. Meanwhile, the joint had a large rotation angle, and the loading was finished.

From the failure mode of the joint, the specimen was accompanied by the accumulation of plastic deformation after entering the yield stage. The yield of the beam flange at the end of the T-steel web was increasingly becoming obvious. Furthermore, the amount of slip between the components was gradually increased. After unloading, an apparent residual deformation occurred, which showed that the yield and plastic stages had significant influences on the restoring force model.

\subsection{Skeleton curve characteristics}

Through the quasi-static test method, the bending momentrotation skeleton curves of the joint specimens were analyzed, as shown in Fig.4. The skeleton curve shows the connection of the hysteresis curve peak points of the specimen under the action of low cyclic reversed load, which can reflect the yield and limit points.

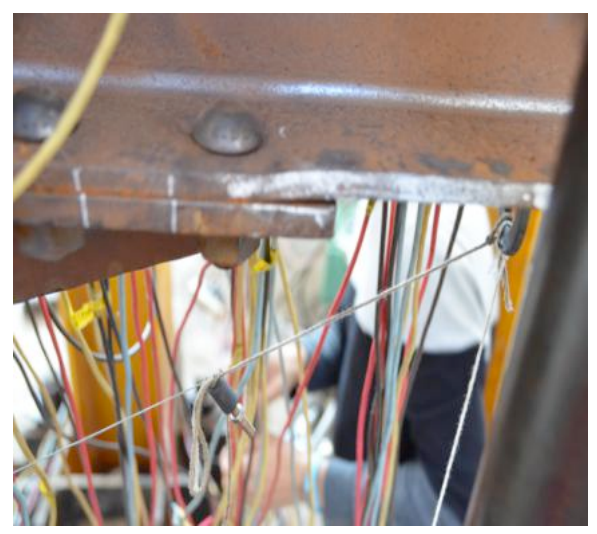

(b) 


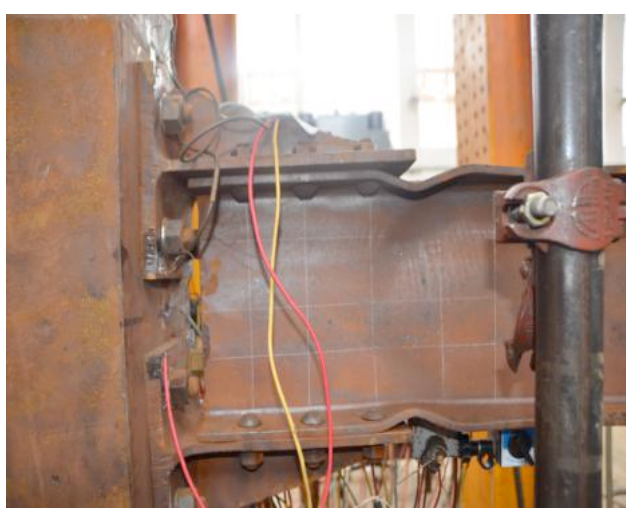

(c)

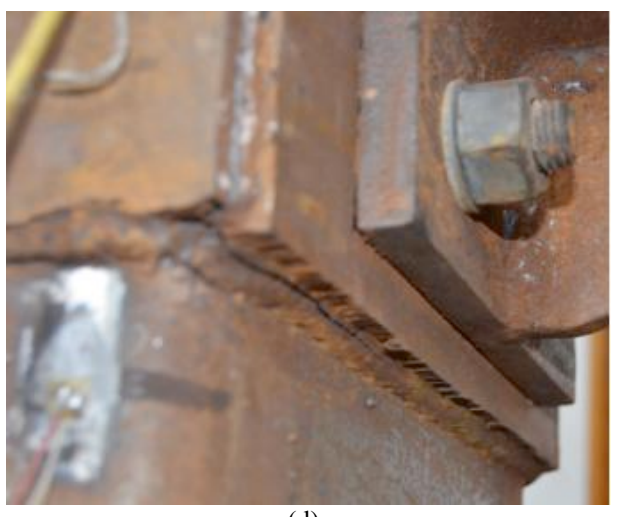

(d)

Fig. 3. Failure mode of the outer shell joint. (a) Gap between T-steel and column flange. (b) Extrusion deformation between bolt and hole wall. (c) Beam flange buckling. (d) Weld cracking of outer shell

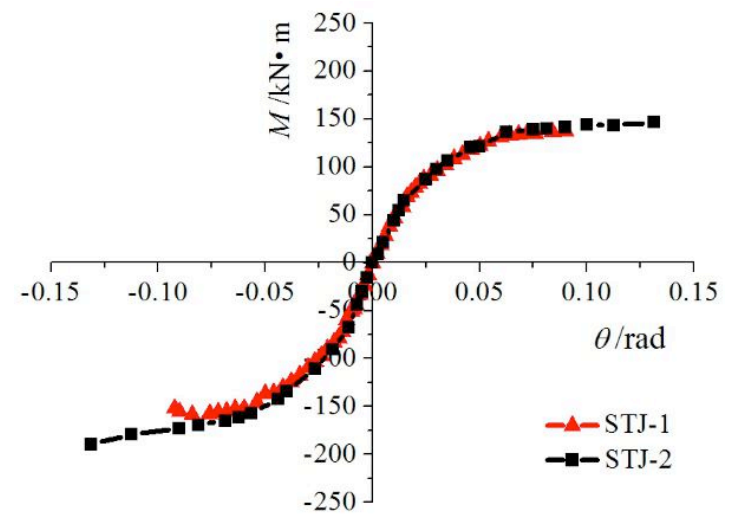

(a)

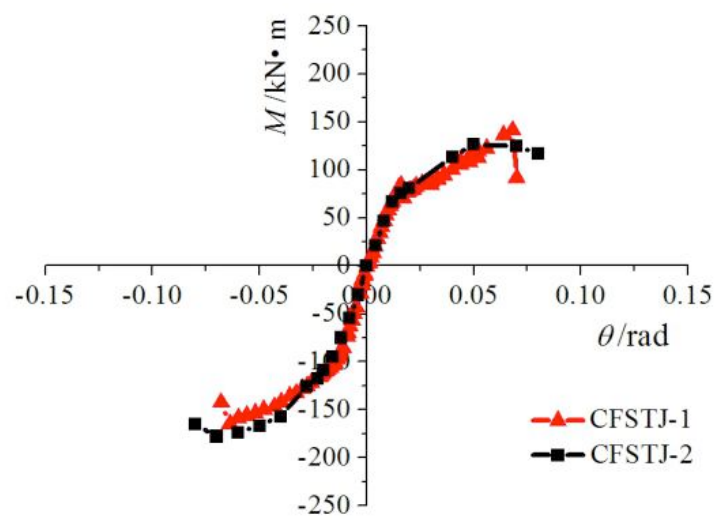

(b)

Fig. 4. Skeleton curves of the test. (a) STJ. (b) CFSTJ

Fig. 4 shows that the loading process of the outer shell joint is divided into three stages: elastic, strengthening, and bearing capacity stabilization stages. The elastic stage is the initial straight line in the skeleton curve. Before the slide of the high-strength bolts, the moment-rotation skeleton curve appears as a straight line, and the stiffness of the outer shell joint remained unchanged. Strengthening is the stage of the initial change of the skeleton curve slope. This stage demonstrates the deceleration of the joint's load growth, but still showed an increasing tendency. At the same time, the stiffness of the specimen decreased, and the nonlinear characteristics occurred caused by the plastic accumulation of the joints in the loading process. The bearing capacity stability stage is the peak segment of the skeleton curve, which is basically in the horizontal level. In this stage, the bearing capacity of the joint is relatively stable. However, the rotational deformation is growing. The specimen is formed into a plastic hinge under repeated loading, and the joint is finally destroyed.

The three stages of the skeleton curve trend were basically the mechanical explanation of the stress process (elasticity, yield, and plasticity) of the specimen, which reflected the stress characteristics of the outer shell joint under the action of low cyclic reversed load.

\subsection{Restoring force model of outer shell joints}

The load-displacement curve obtained by the reciprocating load is called the hysteresis curve, the outer envelope of the hysteresis curve is the skeleton curve, and the two curves are collectively referred to as restoring force curve. The restoring force model is a practical mathematical model simplified by the restoring force curve of the experiment.

\subsubsection{Simplification of the restoring force model}

The restoring force model used the mathematical method to simplify the load-deformation relation in the test results. In order to approach the test curves, the simplified process should be equivalent to the original model in the following aspects:

(1) The maximum value of the elastic load point was chosen as yield point. In the elastic stage, the loading and unloading stiffness of the specimen were unchanged, namely, the linear initial stiffness.

(2) The tri-linear restoring force model was adopted, and the stiffness degradation after the yield and ultimate load was considered.

(3) The test results showed no obvious descending branch of the moment-rotation curve of the joint specimen. Therefore, the skeleton curve of the outer shell joint adopted the tri-linear model, as shown in Fig. 5. In this curve, the third branch is represented by the horizontal line. The bending moment was constant after reaching the ultimate bearing capacity.

\subsubsection{Skeleton curve model}

The tri-linear model of moment-rotation skeleton curve is shown in Fig. 5. This curve involved four parameters: elastic stiffness $K_{0}$ (initial stiffness), yield bearing capacity $M_{y}$, ultimate bearing capacity $M_{u}$, and ultimate rotation angle $\theta_{u}$ corresponding to ultimate bearing capacity. The yield bearing capacity $M_{y}$ was determined by the point where the elastic phase slope of the skeleton curve was significantly 
changed, $\theta_{y}$ was yield rotation angle. Since the test curves did not have obvious descending segments, the bearing capacity $M_{u}$ selected the peak load $M_{\max }$.

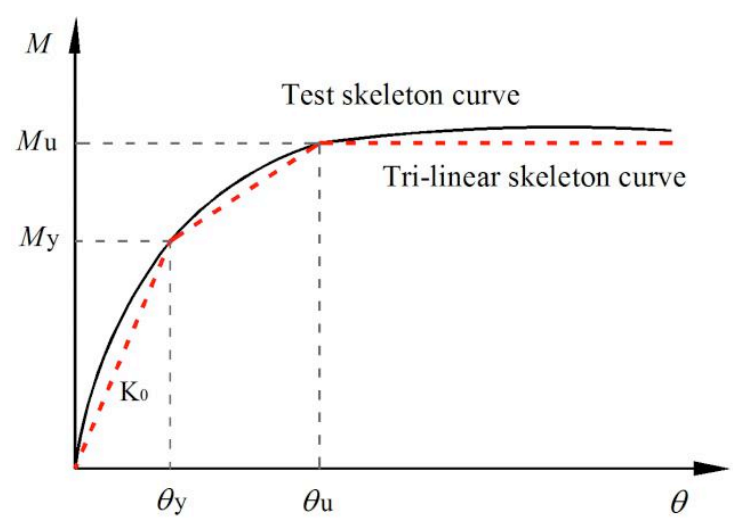

Fig. 5. Tri-linear model of moment-rotation relationship

Due to the difference of the ultimate bearing capacities and the limit displacements of the four joints, obtaining a unified expression formula was difficult. In order to facilitate the analysis and application, the dimensionless processing of the skeleton curves of the specimens was carried out, i.e., the abscissa was $\theta / \theta_{u}$, and the ordinate was $M / M_{u}$. After the regression analysis of the experimental data, the dimensionless skeleton curves can be obtained, as shown in Fig. 6. The linear equations at each stage of the skeleton curve model were shown in Table 3, where $M_{u}^{+}$and $M_{u}^{-}$were positive and negative ultimate loads, respectively. By the regression analysis, the skeleton curves of the specimens are noted as having similar change rules, and the values of the feature points were approximately the same.

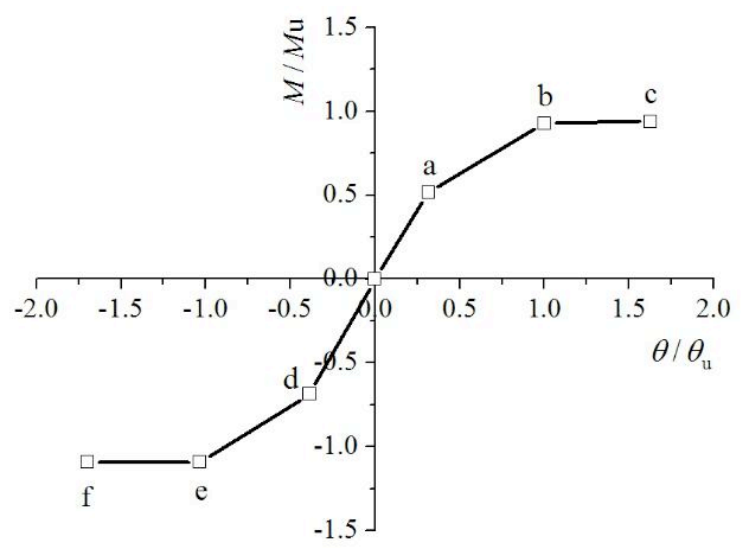

Fig. 6. Tri-linear skeleton curve model

As shown in Fig. 6, the slopes of the oa and od segments in the tri-linear skeleton curve model were obtained by regression analysis of loading and unloading stiffness before the yielded joint, indicating the relative elastic stiffness of the specimen. The slopes of $\mathrm{ab}$ and de two line segments were obtained by the regression analysis from the yield of joint to the peak load under the cyclic loading, which represented the plastic stiffness of the specimen after yield. The segments bc and ef were obtained by regression analysis after the joint reached the ultimate bearing capacity. Since the variation of the bearing capacity of this stage was small, the third segment was fitted into the horizontal line.

Table 3. Mathematical expressions of skeleton curve model

\begin{tabular}{l|l|l|l}
\hline Line segment & Regression equation & Horizontal angle (degree) & Slope \\
\hline oa & $M / M_{u}^{+}=1.628\left(\theta / \theta_{u}\right)$ & $58.44^{\circ}$ & 1.628 \\
ab & $M / M_{u}^{+}=0.471\left(\theta / \theta_{u}\right)+0.366$ & $25.22^{\circ}$ & 0.471 \\
bc & $M / M_{u}^{+}=0.930$ & $0^{\circ}$ & 0 \\
od & $M / M_{u}^{-}=1.915\left(\theta / \theta_{u}\right)$ & $62.43^{\circ}$ & 1.915 \\
de & $M / M_{u}^{-}=0.505\left(\theta / \theta_{u}\right)-0.506$ & $26.79^{\circ}$ & 0.505 \\
ef & $M / M_{u}^{-}=-1.093$ & $0^{\circ}$ & 0 \\
\hline
\end{tabular}

\subsubsection{Stiffness degradation rules}

After the specimen yield, a certain degree of stiffness degradation was observed in the loading and unloading stages. Through the regression analysis of the momentrotation curve data of the specimens under the reciprocating load, the degeneration rules of stiffness are expressed at different stages. Among them, $K_{1}$ and $K_{3}$ were positive and negative unloading stiffness, respectively, while $K_{2}$ and $K_{4}$ were negative and positive loading stiffness, respectively, as shown in Fig. 7.

(1) Positive unloading stiffness $K_{1}$

As shown in Fig. 7, point $\mathrm{A}$ is the positive unloading point, point $\mathrm{B}$ is the corresponding point when the positive force was unloaded to zero, the line segment $\mathrm{AB}$ connected by the two points is the positive unloading line, and its slope is the positive unloading stiffness $K_{1}$. According to the regression analysis of the test data, the relationship between
$K_{1} / K_{0}^{+}$and $\theta_{1} / \theta_{u}^{+}$is shown in Fig. 8, where $K_{0}^{+}$represents the initial stiffness of positive loading, $\theta_{1}$ is the rotation angle corresponding to the positive unloading point, and $\theta_{u}^{+}$ corresponds to the rotation angle of positive peak load. The unloading stiffness can be expressed as logarithmic equation by regression analysis, as shown in Equation 1.

$$
K_{1} / K_{0}^{+}=-0.198 \ln \left(\theta_{1} / \theta_{u}^{+}\right)+0.738
$$

(2) Negative loading stiffness $K_{2}$

As shown in Fig. 7, point $\mathrm{B}$ is the residual deformation point of the positive unloading of the joint specimen, while the corresponding residual deformation value is $\theta_{1}^{\prime}$. The point $\mathrm{C}$ is shown as a negative unloading point, while the line segment $\mathrm{BC}$ is the negative loading line. The slope of the line segment $\mathrm{BC}$ is the negative loading stiffness $K_{2}$. This segment is related to the number of reciprocating loads of the joint specimen, the residual plastic deformation when 
unloading to zero, and the initial stiffness of the negative loading. The relationship between $K_{2} / K_{0}^{-}$and $\theta_{1}^{\prime} / \theta_{u}^{+}$can be obtained through the regression analysis, as shown in Fig. 9 , where $K_{0}^{-}$is the initial stiffness of the joint in negative loading. The negative loading stiffness can be expressed as the exponential equation after regression analysis, as seen in Equation 2.

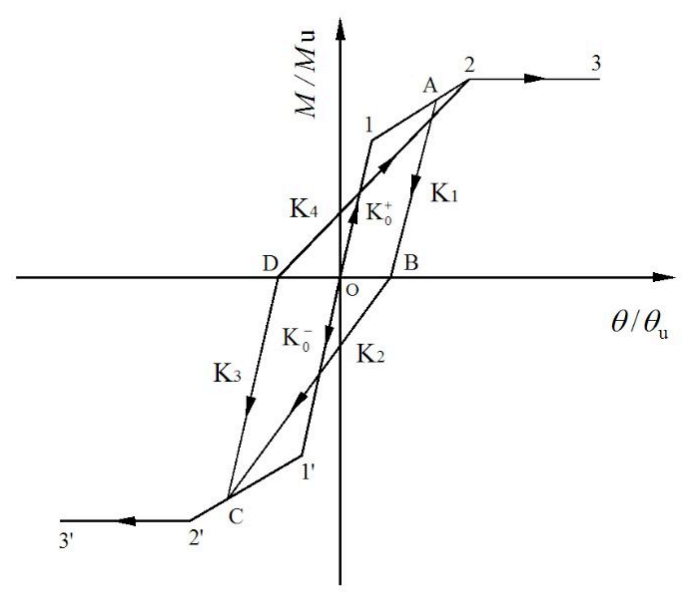

Fig. 7. Stiffness degradation rules

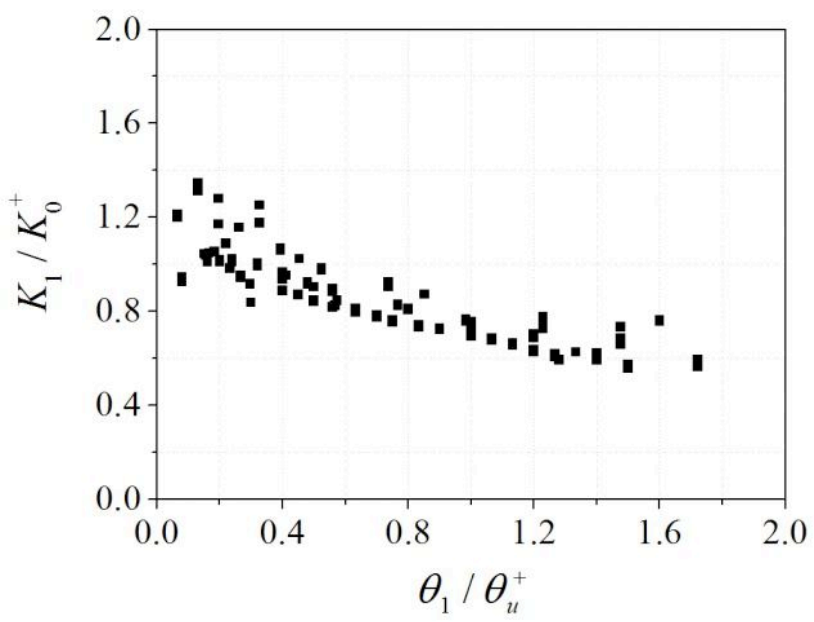

Fig. 8. Degradation rule of $K_{1}$

$K_{2} / K_{0}^{-}=0.724 e^{-1.358\left(\theta_{1}^{\prime} / \theta_{u}^{+}\right)}$

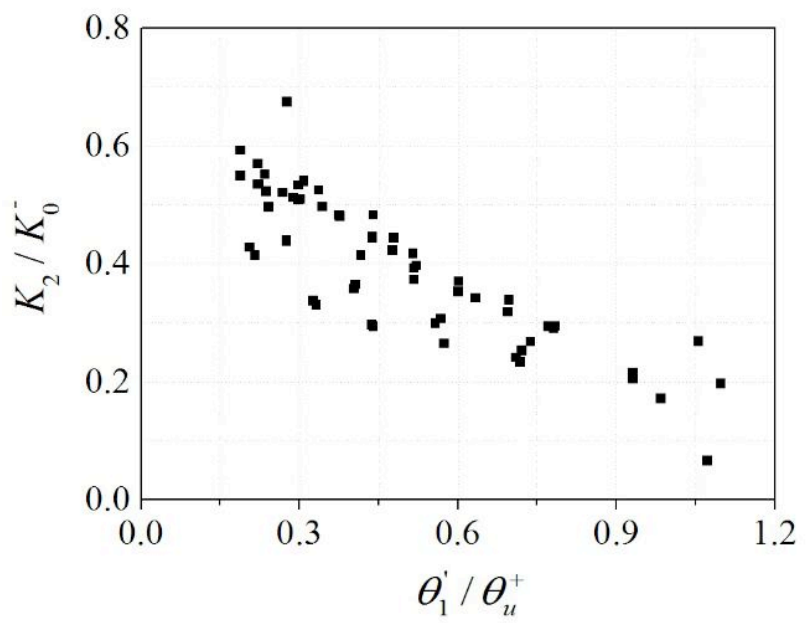

(3) Negative unloading stiffness $K_{3}$

As shown in Fig. 7, point $\mathrm{D}$ is the point when the negative force was unloaded to zero, $\theta_{2}$ is the displacement corresponding to the negative unloading point, the line segment $\mathrm{CD}$ is the negative unloading line, and its slope is the negative unloading stiffness $K_{3}$. According to the regression analysis of the test data, the relationship between $K_{3} / K_{0}^{-}$and $\theta_{2} / \theta_{u}^{-}$is shown in Fig. 10. This relationship can be expressed as a logarithmic relationship, as shown in Equation 3, where $K_{0}^{-}$represents the initial stiffness of negative loading, and $\theta_{u}^{-}$represents the rotation angle corresponding to the negative peak load.

$K_{3} / K_{0}^{-}=-0.23 \ln \left(\theta_{2} / \theta_{u}^{-}\right)+0.828$

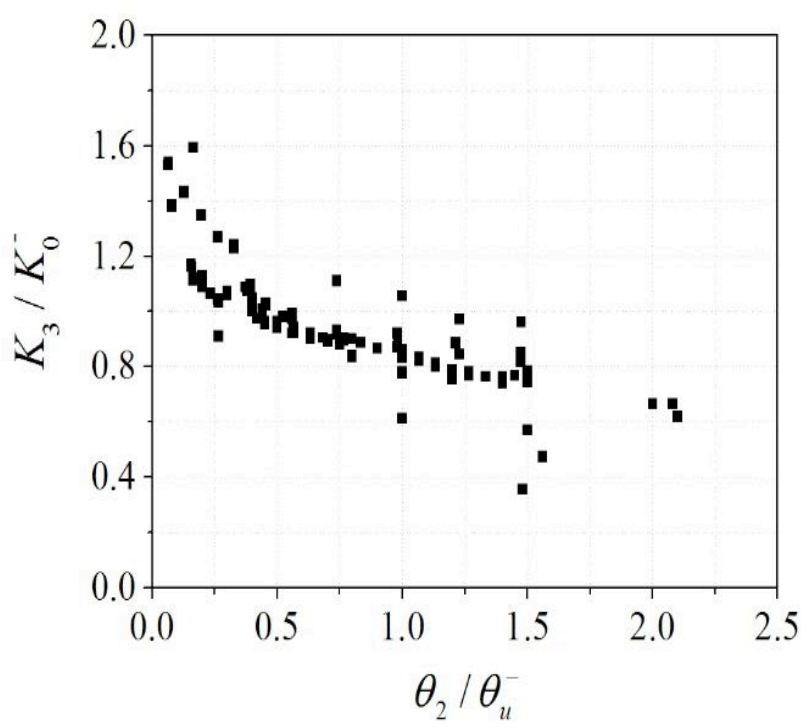

Fig. 10. Degradation rule of $K_{3}$

(4) Positive loading stiffness $K_{4}$

As shown in Fig. 7, the residual point $\mathrm{D}$ of the negative force unloaded to zero connects with the positive unloading point $\mathrm{A}$, line segment DA is the positive loading line, and the slope of line segment DA is the positive loading stiffness $K_{4}$. This segment is related to the degradation rules of the positive and negative loading stiffness, the number of cycles of the load, the residual deformation when unloading to zero, and the initial stiffness under the bending moment. $\theta_{2}^{\prime}$ is the residual deformation when the negative force unloaded to zero. The relationship between $K_{4} / K_{0}^{+}$and $\theta_{2}^{\prime} / \theta_{u}^{-}$can be obtained through the regression analysis, as shown in Fig. 11. It can be expressed as an exponential relationship, as shown in Equation 4.

$$
K_{4} / K_{0}^{+}=0.499 e^{-1.087\left(\theta_{2}^{\prime} / \theta_{u}^{-}\right)}
$$

Through the regression analysis of the stiffness degradation data in the test results, the positive and negative unloading stiffness $\left(K_{1}\right.$ and $\left.K_{3}\right)$ showed good logarithmic relationships with joint rotation angle, while the negative and positive loading stiffness $\left(K_{2}\right.$ and $\left.K_{4}\right)$ had good exponential relationships with the rotation angle.

Fig. 9. Degradation rule of $K_{2}$ 


\subsubsection{Hysteresis curve model}

Under the low cycle reciprocating load, a tri-linear restoring force model of outer shell joints was proposed based on the calculation results of the skeleton curves, stiffness degeneration rules, and the trend of hysteresis curves. Its hysteresis rule is shown in Fig. 12.

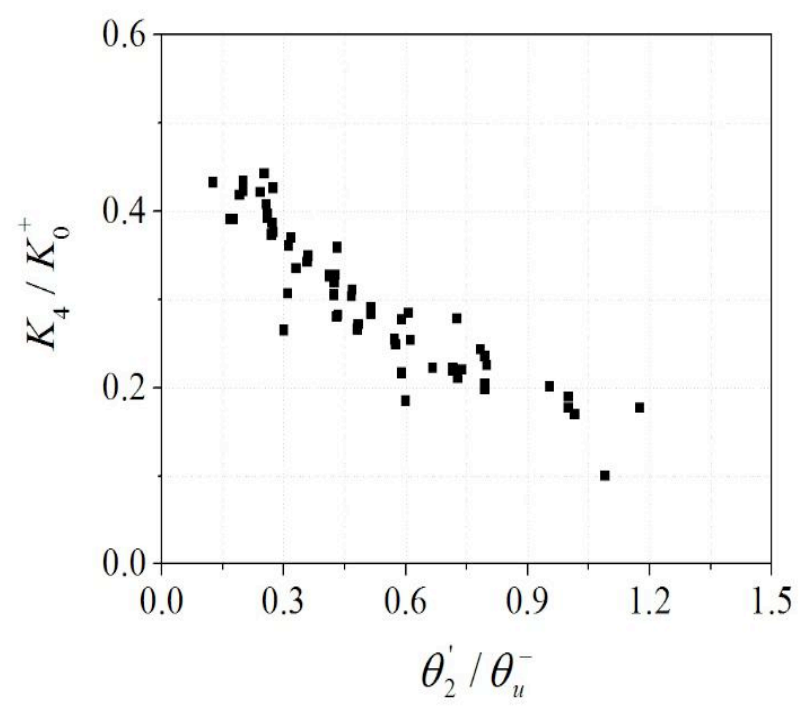

Fig. 11. Degradation rule of $K_{4}$

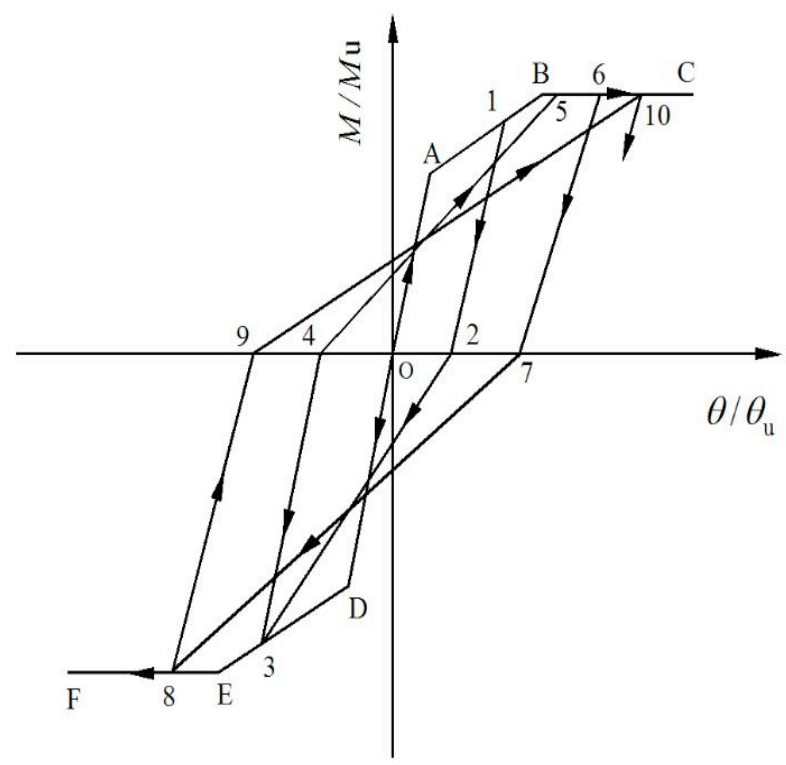

Fig. 12. Restoring force model of outer shell joint

During the initial loading phase, the moment-rotation relationship was carried out along the skeleton curve $\mathrm{O}-\mathrm{A}-$ $\mathrm{B}-\mathrm{C}$. When unloading in the elastic phase $(\mathrm{O}-\mathrm{A})$, the unloading stiffness remained the same as the positive initial stiffness, and the unloading line was $\mathrm{A}-\mathrm{O}$. When the joint entered the yield phase (A-B segment), the unloading path was carried out along the line segment $1-2$, and the stiffness decreased gradually with the increase of the unloading displacement and the number of cycles. The unloading stiffness was calculated according to Equation 1. Then the negative loading was started by unloading point 2 , and the moment-rotation relationship developed along the skeleton curve 2-3-E-F. When the joint reached the negative yield point, it was unloaded from the unloading point 3 . Furthermore, the negative unloading was carried out along line segment 3-4, and the unloading stiffness was calculated according to Equation 3. When the load was unloaded at point 4 , the positive loading was started along line segment 4-5. At the moment, the skeleton curve developed along the skeleton curve $4-5-\mathrm{B}-\mathrm{C}$. Then, the specimen was positively unloaded along the line $6-7$, the negative loading was along the line $7-8$, the negative unloading was along the line $8-9$, and positive loading was along the line 9-10. Then subsequent loading and unloading were carried out in accordance with this cycle.

In summary, combined with the test results, the model adopted the tri-linear model considering the stiffness degradation. This model can better reflect the stiffness degradation rules of the joints with the increase of the deformation and is suitable for the seismic analysis of the steel structure outer shell joints. The established restoring force model of the joints had the following characteristics: (1) Under the action of low cyclic reciprocating load, the positive and negative stiffness of loading and unloading in the elastic phase were initial stiffness. (2) When the joint yielded, the stiffness of loading and unloading gradually degenerated, and it became more apparent with the increase of the displacement and the number of cycles.

\subsection{Verification of restoring force model 4.4.1 Comparison analysis of skeleton curves}

From the regression equation of each segment in the skeleton curve model of Table 3 , the calculated results of the skeleton curves of the four outer shell joints were obtained and compared with the experimental skeleton curves, as shown in Fig. 13. The tri-linear restoring force model can reflect the trend of the test skeleton curves in the process of stress, moreover, it can simulate the moment-rotation relationship of the specimen in the elastic and plastic stages. The simplified tri-linear model was basically consistent with the experimental curve, which verified the rationality of the skeleton curve model.

\subsubsection{Comparison analysis of hysteresis curves}

The hysteresis curves of the specimens can be calculated according to the hysteresis rules of the restoring force model in Fig. 12, which were compared with the experimental hysteresis curves, as shown in Fig. 14. In this figure, the calculated hysteresis curves were similar to those obtained from the experiments, showing that under the condition of low cyclic reversed loading, the proposed restoring force model can better reflect the moment-rotation relationships. This relationship describes the realistic hysteresis behavior of the outer shell joints. 


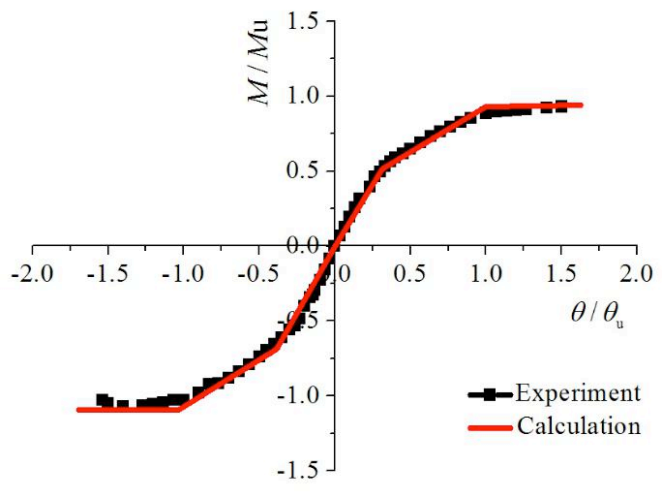

(a)

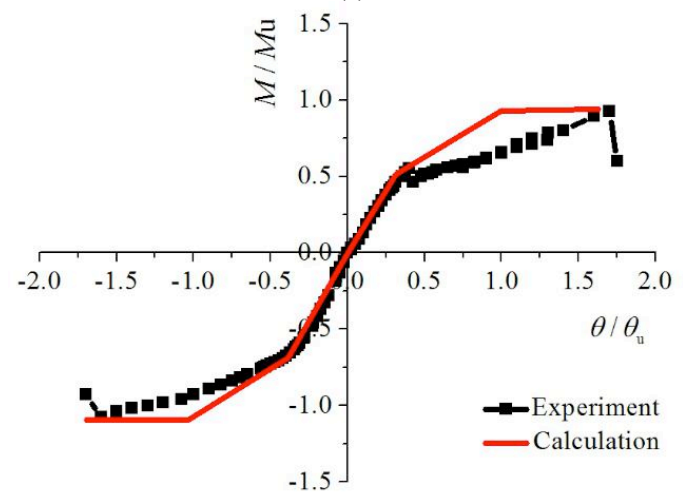

(c)

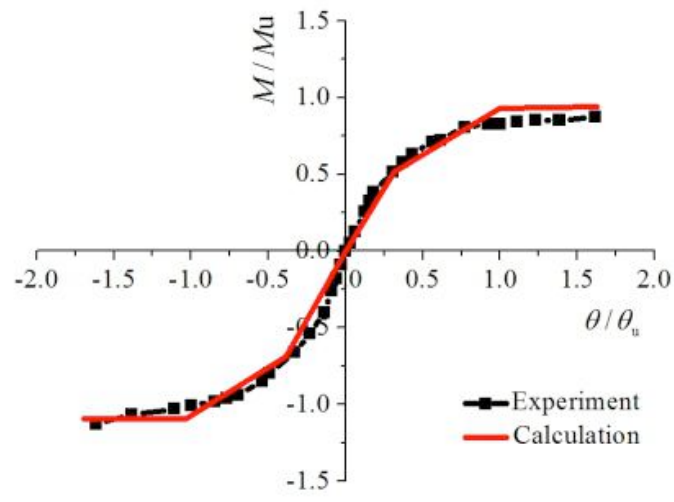

(b)

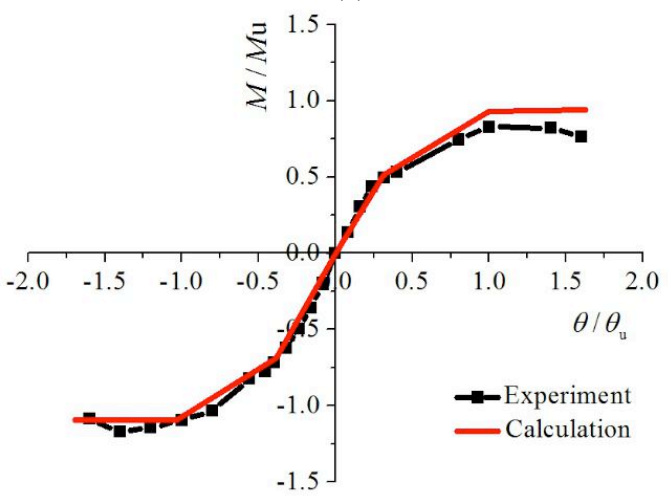

(d)

Fig. 13. Comparison results of $M-\theta$ skeleton curves. (a) STJ-1. (b) STJ-2. (c) CFSTJ-1. (d) CFSTJ-2

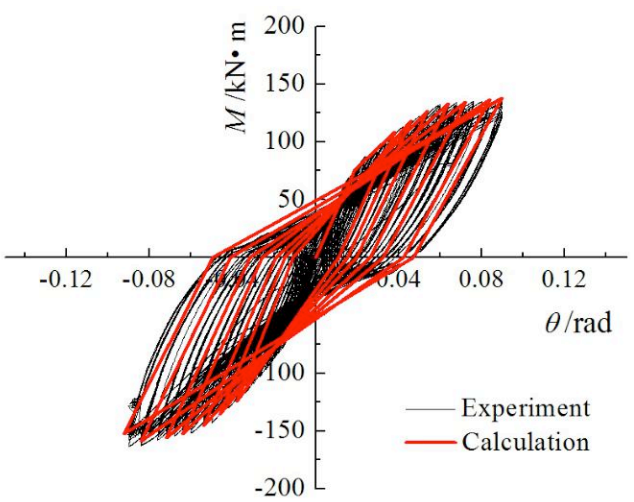

(a)

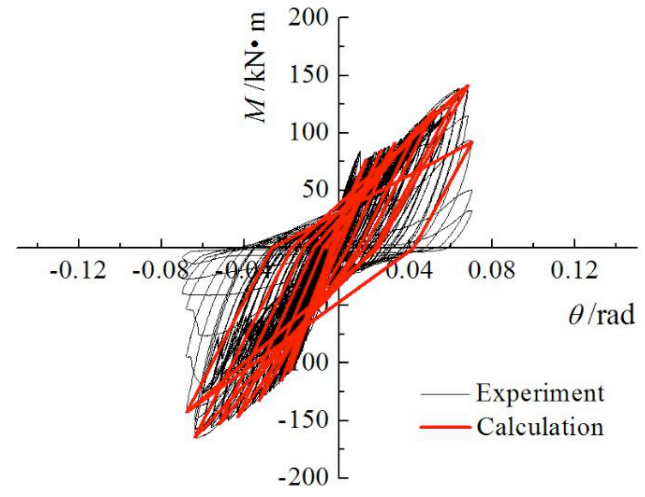

(c)

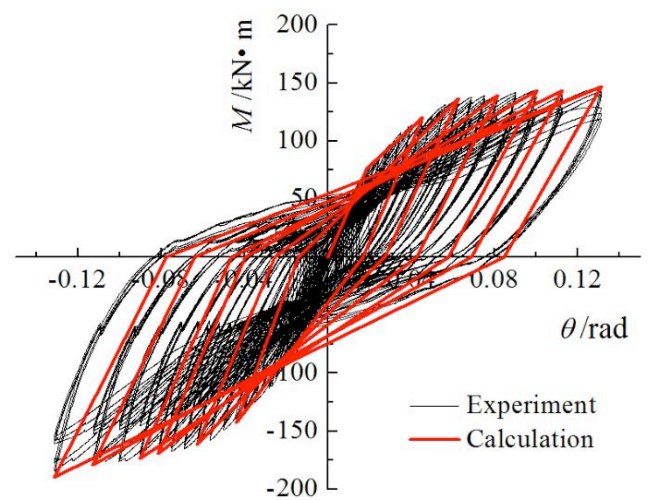

(b)

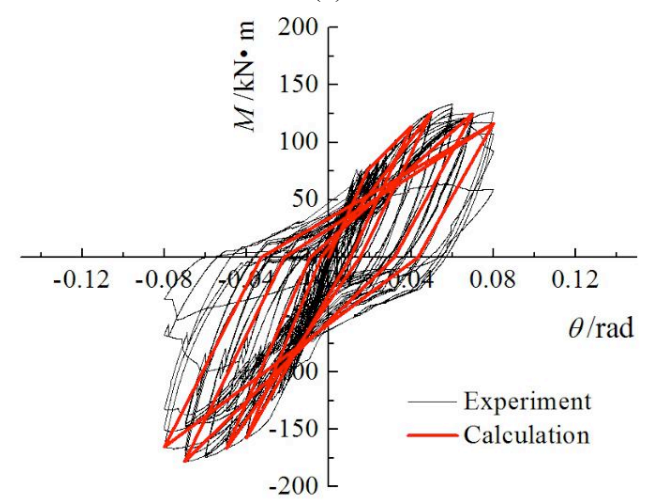

(d)

Fig. 14. Comparison results of $M-\theta$ hysteresis curves. (a) STJ-1. (b) STJ-2. (c) CFSTJ-1. (d) CFSTJ-2

\section{Conclusions}

In order to establish a simple and practical restoring force model of steel structure beam-column outer shell joint, the quasi-static test method was used to study the hysteresis performance of four joint specimens in this study. Based on the regression analysis results of test data, a tri-linear restoring force model suitable for outer shell joint was proposed. In addition, the skeleton curves and hysteresis 
rules were verified experimentally. The following conclusions were drawn:

(1) The stress process of the outer plate joints under cyclic loading can be divided into three stages: elasticity, yield, and plasticity, which is consistent with the trend of skeleton curve.

(2) The established tri-linear skeleton curve model conforms to the stress characteristics of the joint, and the horizontal line is selected as the third branch. At the same time, the dimensionless skeleton curves have similar changing rules, and the feature points are the same.

(3) After the joint specimen yielded, the stiffness degradation rules of loading and unloading are exponential and logarithmic, relating to the rotational deformation. On this basis, the mathematical description of the hysteresis model is presented, and the rationality of the proposed restoring force model is verified.
The restoring force model proposed in this study can describe the mechanical properties of the outer shell joints and provide an accurate reflection of the hysteresis behavior of the specimens. Meanwhile, the model lays the foundation for the elasto-plastic analysis of steel structure. However, the restoring force model simplifies the judgment basis of the feature points of the skeleton curve. Hence, further theoretical study on the calculation method is necessary.

\section{Acknowledgements}

This work was supported by the National Science and Technology Support Program of China (No. 2013BAK13B01).

This is an Open Access article distributed under the terms of the Creative Commons Attribution Licence

\section{References}

1. Li, L. M., Chen, Y. Y., Li, N., Cai, Y. C., "Seismic performance of outer-shell connection of cold-formed square tubular column and $\mathrm{H}$-shaped steel beam". Journal of Jilin University(Engineering and Technology Edition), 40(1), 2010, pp.67-71.

2. Rodrigues, H., Romão, X., Andrade-Campos, A., Varum, H., Arêde, A., Costa, A.G., "Simplified hysteretic model for the representation of the biaxial bending response of RC columns". Engineering Structures, 44, November, 2012, pp.146-158.

3. Yin, X. W., Lu, X. L., Lu, W. S., "Resilience model of SRC columns with cross-shaped encase steel". Engineering Mechanics, 31(1), 2014, pp.97-103.

4. Jiang, L. Q., Zheng, H., Liu, Y., Yuan, X. S., "Experimental investigation of composite steel plate deep beam infill steel frame". International Journal of Steel Structures, 14(3), 2014, pp.479-488.

5. Zhang, H. D., Wang, Y. F., "Energy-based numerical evaluation for seismic performance of a high-rise steel building". Steel and Composite Structures, 13(6), 2012. pp.501-519.

6. Sengupta, P., Li, B., "Modified Bouc-Wen model for hysteresis behavior of RC beam-column joints with limited transverse reinforcement". Engineering Structures, 46, January, 2013, pp.392406.

7. Li, W., Han, L. H., "Seismic performance of CFST column to steel beam joint with RC slab: Joint model". Journal of Constructional Steel Research, 73, June, 2012, pp.66-79.

8. Sivaselvan, M., V., "Hysteretic models with stiffness and strength degradation in a mathematical programming format". International Journal of Non-Linear Mechanics, 51, May, 2013, pp.10-27.

9. Ceravolo, R., Erlicher, S., Fragonara, L., Z., "Comparison of restoring force models for the identification of structures with hysteresis and degradation". Journal of Sound and Vibration, 332(26), 2013, pp.6982-6999.

10. Kumar, M., Whittaker, A., S., Constantinou, M., C., "An advanced numerical model of elastomeric seismic isolation bearings". Earthquake Engineering and Structural Dynamics, 43(13), 2014, pp.1955-1974.

11. Fan, S., G., Ding, Z., X., Du, L., Shang, C., F., Liu, M., J., "Nonlinear finite element modeling of two-stage energy dissipation device with low-yield-point steel". International Journal of Steel Structures, 16(4), 2016, pp.1107-1122.

12. Wang, C. Q., Xiao, J. Z., Pham, L., Ding, T., "Restoring force model of a cast-in-situ recycled aggregate concrete frame". Advances in Structural Engineering, 17(10), 2014, pp.1443-1457.
13. Loh, C. H., Mao, C. H., Huang, J. R., Pan, T. C., "System identification and damage evaluation of degrading hysteresis of reinforced concrete frames". Earthquake Engineering and Structural Dynamics, 40(6), 2011, pp.623-640.

14. Kumar, M., Rai, D., C., Jain, S., K., "Ductility reduction factors for masonry-infilled reinforced concrete frames". Earthquake Spectra, 31(1), 2015, pp.339-365.

15. Xiao, J. Z., Huang, X., Shen, L. M., "Seismic behavior of semiprecast column with recycled aggregate concrete". Construction and Building Materials, 35, October, 2012, pp.988-1001.

16. Mergos, P., E., Beyer, K., "Modelling shear-flexure interaction in equivalent frame models of slender reinforced concrete walls". The Structural design of Tall and Special Buildings, 23(15), 2014, pp.1171-1189.

17. Kashani, M., M., Lowes, L., N., Crewe, A., J., Alexander, N., A., "Phenomenological hysteretic model for corroded reinforcing bars including inelastic buckling and low-cycle fatigue degradation". Computers and Structures, 156, August, 2015, pp.58-71.

18. Li, S. C., Dong, J. X., Li, L. F., "Experimental hysteretic behavior of in-plane loaded reinforced grouted multi-ribbed aerated concrete blocks masonry walls". Structural Engineering and Mechanics, 41(1), 2012, pp.95-112.

19. Eom, T., S., Hwang, H., J., Park, H., G., "Energy-based hysteresis model for reinforced concrete beam-column connections". ACI Structural Journal, 112(2), 2015, pp.157-166.

20. Yu, F., Xu, G. S., Cheng, A. C., "Study on restoring force model of PVC-CFRP tube confined reinforced concrete column". Journal of Building Structures, 36(9), 2015, 66-72.

21. Su, L. W., Wang, Y. T., Cai, J., Long, Y. L., "Restoring force model of concrete-filled square steel tubular columns with binding bars". The Open Civil Engineering Journal, 10, 2016, pp.179-188.

22. Lu, X. L., Yin, X. W., Jiang, H. J., "Restoring force model for steel reinforced concrete columns with high steel ratio". Structural Concrete, 14(4), 2013, pp.415-422.

23. Zhou, C. D., Lu, X. L., Li, H., Tian, T., "Restoring force model for circular RC columns strengthened by pre-stressed CFRP strips". Steel and Composite Structures, 17(4), 2014, pp.371-386.

24. Li, S. C., "Experimental study on restoring force model of high strength concrete columns confined by butt-welded closed composite stirrups". Journal of Building Structures, 37(1), 2016, 41-47. 